\title{
The Potential of Sky Fruit as an Anti-Aging and Wound Healing Cosmeceutical Agent
}

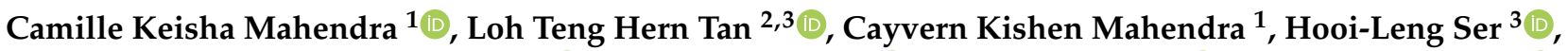

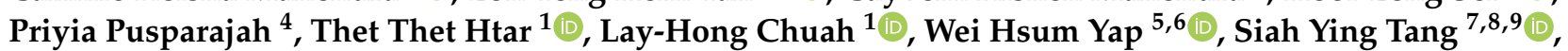 \\ Long Chiau Ming ${ }^{10} \oplus^{\circ}$, Yoon-Yen Yow ${ }^{11, *(\mathbb{B})}$ and Bey Hing Goh $1,12,13, * \mathbb{C}$
}

1 Biofunctional Molecule Exploratory Research Group, School of Pharmacy, Monash University Malaysia, Bandar Sunway, Subang Jaya 47500, Selangor Darul Ehsan, Malaysia; camille.mahendra@monash.edu (C.K.M.); cayvern.kishen@gmail.com (C.K.M.); thet.thet.htar@monash.edu (T.T.H.); alice.chuah@monash.edu (L.-H.C.)

2 Clinical School Johor Bahru, Jeffrey Cheah School of Medicine and Health Sciences, Monash University Malaysia, Johor Bahru 80100, Johor, Malaysia; loh.teng.hern@monash.edu

3 Novel Bacteria and Drug Discovery Research Group, Microbiome and Bioresource Research Strength Jeffrey Cheah School of Medicine and Health Sciences, Monash University, Bandar Sunway, Subang Jaya 47500, Selangor Darul Ehsan, Malaysia; ser.hooileng@monash.edu

4 Medical Health and Translational Research Group, Jeffrey Cheah School of Medicine and Health Sciences, Monash University Malaysia, Bandar Sunway, Subang Jaya 47500, Selangor Darul Ehsan, Malaysia; Priyia.Pusparajah@monash.edu

5 School of Biosciences, Taylor's University, Subang Jaya 47500, Selangor Darul Ehsan, Malaysia; weihsum.yap@taylors.edu.my

check for updates

Citation: Mahendra, C.K.; Tan, L.T.H.; Mahendra, C.K.; Ser, H.-L.; Pusparajah, P.; Htar, T.T.; Chuah, L.-H.; Yap, W.H.; Tang, S.Y.; Ming, L.C.; et al. The Potential of Sky Fruit as an Anti-Aging and Wound Healing Cosmeceutical Agent. Cosmetics 2021, 8, 79. https://doi.org/10.3390/ cosmetics 8030079

Academic Editor: Enzo Berardesca

Received: 3 July 2021

Accepted: 4 August 2021

Published: 31 August 2021

Publisher's Note: MDPI stays neutral with regard to jurisdictional claims in published maps and institutional affiliations.

Copyright: (c) 2021 by the authors. Licensee MDPI, Basel, Switzerland. This article is an open access article distributed under the terms and conditions of the Creative Commons Attribution (CC BY) license (https:// creativecommons.org/licenses/by/ $4.0 /)$.
6 Centre for Drug Discovery and Molecular Pharmacology (CDDMP), Faculty of Health and Medical Sciences (FHMS), Taylor's University, Subang Jaya 47500, Selangor Darul Ehsan, Malaysia

7 Chemical Engineering Discipline, School of Engineering, Monash University Malaysia, Bandar Sunway, Subang Jaya 47500, Selangor Darul Ehsan, Malaysia; Patrick.Tang@monash.edu

8 Advanced Engineering Platform, Monash University Malaysia, Bandar Sunway, Subang Jaya 47500, Selangor Darul Ehsan, Malaysia

9 Tropical Medicine and Biology Platform, School of Science, Monash University Malaysia, Bandar Sunway, Subang Jaya 47500, Selangor Darul Ehsan, Malaysia

10 Pengiran Anak Puteri Rashidah Sa'adatul Bolkiah Institute of Health Sciences, Universiti Brunei Darussalam, Gadong, Bandar Seri Begawan BE1410, Brunei; longchiauming@gmail.com

11 Department of Biological Sciences, School of Medical and Life Sciences, Sunway University, Bandar Sunway, Subang Jaya 47500, Selangor Darul Ehsan, Malaysia

12 College of Pharmaceutical Sciences, Zhejiang University, 866 Yuhangtang Road, Hangzhou 310058, China

13 Health and Well-Being Cluster, Global Asia in the 21st Century (GA21) Platform, Monash University Malaysia, Bandar Sunway, Subang Jaya 47500, Selangor Darul Ehsan, Malaysia

* Correspondence: yoonyeny@sunway.edu.my (Y.-Y.Y.); goh.bey.hing@monash.edu (B.H.G.)

\begin{abstract}
There are many extrinsic factors that can contribute to the premature aging of the skin. In recent years, the demand for natural cosmetic from the general population has noticeable grow. Therefore, this research aimed to investigate the bioproperties of sky fruit (Swietenia macrophylla) seed extract that could help to inhibit premature skin aging. Firstly, the extract and its fractions were tested on $\mathrm{HaCaT}$ cells for their wound healing properties. The presence of sky fruit's extract and its fractions on scratch wound significantly improved cellular proliferation, migration, and closure of the wound. These effects were distinctly observed following the treatment with S. macrophylla hexane fraction (SMHF) and S. macrophylla water fraction (SMWF). Our continuous research study revealed that SMWF had antioxidant properties, which might be one of the factors contributing to its emerging wound healing properties because antioxidants are known to act as suppressors of the inflammatory pathway and aid the transition towards cell proliferation. In addition, all samples had critical wavelengths that indicated that they were able to absorb the whole UVB range and some parts of the UVA wavelength. This suggested that $S$. macrophylla might contain potential photoprotective bioactive compounds, which could be developed into anti-UVB photoprotective sunscreens. Thus, this warrants further studies focusing on isolation and identifications of the bioactive compounds responsible for both its photoprotective and wound healing properties. A
\end{abstract}


deeper study on mechanisms of the pathways that were affected by these compounds should be conducted as well to better understand this natural product and develop it into a potential cosmeceutical ingredient.

Keywords: cosmeceutical; anti-aging; anti-pigmentation; wound healing; Swietenia macrophylla; natural product; cosmetics; photoprotection

\section{Introduction}

The term of cosmetics does not only cover items such as make-up and skincare products but also daily personal hygienic consumables, such as soap, toothpaste, perfume, etc. [1]. Hence, it is unthinkable that we could live without cosmetics. The term cosmeceuticals came into play in the cosmetic industry in 1984, when it was coined by Albert Kligman. It means the combination of both "cosmetics" and "pharmaceuticals" and defines products that have both cosmetic and therapeutic properties [2]. Although various grooming products fall into the category of cosmetics, there had been a continuous growth in consumer trends towards skincare cosmetics. In recent years, it could be seen that the market itself is now no longer contained towards women but had expanded towards men as well as; many are drawn towards the benefits of skincare cosmetics in boosting their appearance and confidence [3].

One way to retain skin youthfulness is to combat premature skin aging. Premature skin aging is characterized by the formation of fine lines and wrinkles, irregular pigmentation, lack of resilience, poor texture, and sagging of the skin [4,5]. A variety of intrinsic and extrinsic factors-for example, a person's genetic make-up, hormonal changes, photodamage by the sun, and diet-can contribute to a person's skin aging [6,7]. Hence, to appeal to the general public, a key feature that many cosmeceuticals claim to have is its ability to slow down the aging process of the skin [8,9]. However, in this current trend, a product being just a cosmeceutical still would not suffice as there is also a growing demand for natural cosmetics due to increased health and environmental consciousness [10]. To meet that demand, many cosmetic companies have introduced many naturally available active ingredients with therapeutic properties, such as skin whitening, antioxidation, wound healing pro-collagen, UV-protective, etc., into their products [11]. Subsequently, another important aspect cosmetic companies must tackle is the problems that arise during the process of wound healing or skin repair. Multiple factors, such as acne, burns, injuries, or surgery, can lead to facial scarring [12-14]. To worsen the matter, scars may also form keloids or hypertrophic scars due to excess tissue formation or become hyperpigmented, leading to further facial disfiguration $[13,15,16]$. Moreover, patients who experience severe burns or injury require medicine or ways that could quickly induce reepithelization of the skin [17].

Therefore, in the present study, we evaluated the bioactive properties of Swietenia macrophylla seed for its potential application as a cosmeceutical agent. Traditionally, plants such as S. macrophylla King had been used as medicine to treat sickness and diseases. S. macrophylla is a tropical timber tree from the tropics of Mexico and Central America. It is part of the Meliaceae family and is very prized for its mahogany wood; hence, it is also widely planted in Southeast Asia $[18,19]$. Besides being prized for its wood, the seeds, also known as "sky fruit", had been traditionally used as a folk medicine to treat diabetes, pain, and hypertension [20]. To confirm such claims, several studies regarding its medicinal properties had been done and the seed was found to possess various bioproperties. Studies by Goh and Abdul Kadir [20] and Low et al. [21] have shown that S. macrophylla ethyl acetate fraction (SMEAF) of the seed extract exhibited anti-cancer properties against HCT116 colon carcinoma cell line, while another study by Sayyad et al. [22] reported that SMEAF also displayed neuroprotective activity on primary neuronal cells. Besides that, the seed extract was also found to induce anti-hyperglycemic activity in rats, while the limonoid 
compounds isolated from the seeds were reported to have anti-viral activity against the dengue virus $2[19,23]$. In our research, we proceeded to extract the crude ethanolic extract, S. macrophylla crude extract (SMCE), from the seed using ethanol. Based on compound polarity, the SMCE was further segregated into SMHF, SMEAF, and SMWF, using solventsolvent fractionation. The results of our analysis showed that all the samples displayed wound healing properties on human keratinocyte cells. Further testing also revealed that SMWF had antioxidant properties, which can aid in the process of wound healing by reducing skin inflammation. Finally, all samples showed that they were also able to absorb within the UVB range and some portions of the UVA radiation. This suggests that not only does $S$. macrophylla seed extract and its fraction have potential wound healing properties, but it has photoprotective properties as well. Hence, it could be suggested that $S$. macrophylla has great potential as a novel candidate for an active ingredient in cosmeceuticals.

\section{Materials and Methods}

\subsection{Materials}

All the chemicals and solvents utilized in this study were of analytical grade. For the extraction, non-denatured ethanol, hexane, ethyl acetate, and $100 \%$ dimethyl sulfoxide (DMSO) were purchased from Thermo Fisher (Waltham, MA, USA). Cell culture media and nutrients, such as DMEM medium, fetal bovine serum (FBS), Tryple E, and antibiotics were supplied by Gibco (New York, NY, USA). On the other hand, phosphate buffer saline, 3-(4,5-dimethylthiazol-2-yl)-2,5-diphenyltetrazolium bromide (MTT), FolinCiocalteu reagent, sodium carbonate, gallic acid, 2,2-diphenyl-1-picrylhydrazyl (DPPH), ethylenediaminetetraacetic acid (EDTA), 2,2'-azino-bis(3-ethylbenzothiazoline-6-sulfonic acid) (ABTS), potassium persulfate, $\mathrm{FeSO}_{4}$, and ferrozine were obtained from Sigma Aldrich (St. Louise, MO, USA). The HaCaT cell line, which was deposited by Deutsches Krebsforschungszentrum (DKFZ) (Heidelberg, Germany), was obtained from Cell lines Service (CLS) (Eppelheim, Germany).

\subsection{Plant Material}

Dried S. macrophylla seeds $(3 \mathrm{~kg})$ were purchased from a local market in Temerloh, Malaysia, and a voucher specimen (No. KLU46901) of the seeds was deposited at the Herbarium of Institute of Biological Sciences, Faculty of Science, University of Malaya, Malaysia.

\subsection{Bioactive Compound Extraction}

The extraction method for the bioactive compounds was as described by Goh et al. [24]. Briefly, the seeds were finely grounded and left to soak in ethanol at room temperature for $72 \mathrm{~h}$. The mixture was then filtered and concentrated using a rotary vacuum evaporator at $40{ }^{\circ} \mathrm{C}$. Portions of SMCE were stored at $-20{ }^{\circ} \mathrm{C}$ for further bioassay screening, while the rest of the extract was processed using solvent-solvent fractionation. Hexane was firstly used to dissolve SMCE and the fraction was dried with anhydrous sodium sulphate before concentrating with a rotary vacuum evaporator to SMHF. Insoluble hexane residues were subjected to a 1:1 solvent-solvent portioning with ethyl acetate and water. Both ethyl acetate and water portions were separated, filtered, and dried using rotary evaporation and freeze-drying to produce SMEAF and SMWF, respectively.

\subsection{Total Phenolic Content (TPC) Analysis}

The total phenolic content of the aqueous fraction was determined using the FolinCiocalteu reagent and a method adapted from Tan et al. [25]. Ten microliters of SMWF at varying concentrations were added to $50 \mu \mathrm{L}$ of $10 \times$ diluted Folin-Ciocalteu reagent in a 96-well microplate. After incubating at room temperature in the dark for $5 \mathrm{~min}, 40 \mu \mathrm{L}$ of $7.5 \%$ sodium carbonate was pipetted into each well. The plate was incubated for another 
$30 \mathrm{~min}$ at room temperature. The absorbance was measured at $750 \mathrm{~nm}$ with a microplate reader and the results obtained were expressed in equivalents of gallic acid (GAEs).

\subsection{Cell Culture}

$\mathrm{HaCaT}$, an immortalized human keratinocyte cell line, was used to emulate the effect of S. macrophylla extract and its fractions on epidermal cells. The cells were maintained using $1 \times$ high glucose DMEM supplemented with Glutamax without HEPES, $1.0 \%$ antibioticantimycotic solution $(100 \mathrm{U} / \mathrm{mL}$ penicillin, $100 \mu \mathrm{g} / \mathrm{mL}$ streptomycin, and $25 \mu \mathrm{g} / \mathrm{mL}$ amphotericin $\mathrm{B}$ ), and $10.0 \% \mathrm{FBS}$ at $37{ }^{\circ} \mathrm{C}$ in $5 \% \mathrm{CO}_{2}$ atmosphere [26].

\subsection{Determination of Cell Cytotoxicity}

The cytotoxicity of S. macrophylla extract on HaCaT cells was assessed using the MTT assay. First, HaCaT cells were seeded in 96-well plates at a density of $1 \times 10^{5}$ cells $/ \mathrm{mL}$. After $24 \mathrm{~h}$, the cells were treated with various concentrations $(0,5,50$, and $100 \mu \mathrm{g} / \mathrm{mL}$ ) of SMCE, SMHF, SMEAF, and SMWF for $24 \mathrm{~h}$. The cell viability was then measured by adding $20 \mu \mathrm{L}$ of MTT into each well. The solution was removed after $2 \mathrm{~h}$ of incubation and the formazan crystals were dissolved in $100 \mu \mathrm{L}$ of $100 \%$ DMSO. The absorbance was measured at $570 \mathrm{~nm}$ using a microplate reader. The percentage of cell viability was obtained by normalizing to the non-treated control.

\subsection{Wound Healing Assay}

HaCaT cells were seeded in a 6-well plate at a cell density of 500,000 cells/well and were incubated. After $24 \mathrm{~h}$, the cells were scratched with a $0.5-10 \mu \mathrm{L}$ clear white pipette tip to create a wound. To remove the detached cells, the cells were rinsed twice with PBS. For the negative control and samples, no FBS was added into the media, while the positive control was treated with $20 \% \mathrm{FBS}$. Images of the wound were taken at time 0 and $24 \mathrm{~h}$ after incubation. The images were processed using Image $1.52 \mathrm{a}$, developed by National Institute of Health (Bethesda, MD, USA), to determine the decrease in the area.

\subsection{Antioxidant Assays}

2.8.1. DPPH Radical Scavenging Activity of the S. macrophylla Extract

The method used was previously described by Tan et al. [25]. Firstly, 0.016\% (w/v) DPPH reagent was prepared using $95 \%$ ethanol and $95 \mu \mathrm{L}$ of the reagent was added into each well of a 96-well microplate. Then, $5 \mu \mathrm{L}$ of the extract at varying concentrations was added into the wells. The reaction was kept in the dark for $20 \mathrm{~min}$ before its absorbance was measured with a microplate reader at $515 \mathrm{~nm}$. The percentage of DPPH scavenging activity was determined based on the Equation (1). Gallic acid was used as the positive control in this assay.

$$
\% \text { DPPH scavenging activity }=\frac{\text { Absorbance of control-Absorbance of sample }}{\text { Absorbance of control }} \times 100 \%
$$

\subsubsection{ABTS Radical Scavenging Assay}

The extract of $S$. macrophylla was subjected to the ABTS radical scavenging assay as described by Ser et al. [27]. Firstly, $7 \mathrm{mM}$ of ABTS stock solution was mixed with $2.45 \mathrm{mM}$ potassium persulfate for $24 \mathrm{~h}$ to produce ABTS radical cations. Varying concentrations of S. macrophylla extract were then mixed with ABTS radical solution in a 96-well microplate. The reaction was kept in the dark for $20 \mathrm{~min}$ at room temperature. Finally, the absorbance was read at $734 \mathrm{~nm}$ with a microplate reader. As a positive control, gallic acid was used and the percentage of ABTS scavenging activity was determined based on Equation (2).

$$
\% \text { ABTS scavenging activity }=\frac{\text { Absorbance of control-Absorbance of sample }}{\text { Absorbance of control }} \times 100 \%
$$




\subsubsection{Ferrous Ion Chelating Assay}

The ferrous ion chelating activity of $S$. macrophylla extract was measured according to the method described by Adjimani and Asare [28]. Varying concentrations of S. macrophylla extract were added to $2 \mathrm{mM} \mathrm{FeSO}_{4}$ in a 96-well microplate. After that, $5 \mathrm{mM}$ of ferrozine was added to the mixture and the plate was incubated at room temperature for $10 \mathrm{~min}$. The absorbance was measured using a microplate reader at $562 \mathrm{~nm}$. In this assay, the positive control was EDTA. The percentage of iron chelating activity was calculated using Equation (3).

$$
\% \text { Iron chelating acitivy }=\frac{\text { Absorbance of control-Absorbance of sample }}{\text { Absorbance of control }} \times 100 \%
$$

\subsection{UVA and UVB Absorption Spectrum of Extract and Its Fractions}

The absorption spectrum of each fraction and extract were measured based on the methods described by Mahendra et al. [29]. Briefly, the extract and its fractions were firstly dissolved in 100\% DMSO and their absorbance was read using BioTek Eon UV/Vis spectrophotometer by Fisher Scientific (Waltham, MA, USA) using a UV transmittable 96-well plate from Corning (New York, NY, USA). The absorbance spectrum was normalized against the absorbance spectrum of DMSO and from there, the critical wavelength of the extract and its fractions were calculated using the curve fitting tool available in MATLAB 2019a, developed by MathWorks (Natick, MA, USA). The critical wavelength of each fraction and extract were calculated based on the formula developed by Diffey [30], as can be seen in Equation (4). According to this formula, the critical wavelength $\left(\lambda_{c}\right)$ represents the point where $90 \%$ of the total integral area is under the curve, from $290 \mathrm{~nm}$ onwards.

$$
\int_{290}^{\lambda_{c}} A(\lambda) d \lambda=0.9 \int_{290}^{400} A(\lambda) d(\lambda)
$$

\subsection{Statistical Analysis}

The results obtained were expressed as mean \pm standard deviation of means (SD) and were statistically analyzed using the Statistical Package for Social Science (SPSS) 16.0, developed by IBM (Armonk, NY, USA). To compare the means of multiple groups, one-way analysis of variance (ANOVA) and post hoc Tukey test were used. When $p \leq 0.05$, the difference was considered statistically significant.

\section{Results}

\subsection{Assessment of Cytotoxicity of the Extract and Its Fraction on HaCaT Cells}

To determine the non-cytotoxic concentration of each extract and its fractions towards the HaCaT cells, the cells were treated at various concentrations and incubated for $24 \mathrm{~h}$. The viability of the cells was measured using the MTT assay after the incubation period and the percentage of viable cells was calculated by normalizing against the non-treated control. As seen in Figure 1, SMCE significantly increased cell death at the concentration of $12.5 \mu \mathrm{g} / \mathrm{mL}$, while SMEAF induced cell death at $25 \mu \mathrm{g} / \mathrm{mL}$. This was followed by SMWF, which induces cell toxicity at $100 \mu \mathrm{g} / \mathrm{mL}$. Finally, HaCaT cells treated with SMHF did not display any cell toxicity even at the concentration of $100 \mu \mathrm{g} / \mathrm{mL}$. In terms of toxicity, the fractions rank SMCE $>$ SMEAF $>$ SMWF $>$ SMHF, SMCE being the most cytotoxic of all samples against $\mathrm{HaCaT}$ cells. Therefore, based on the obtained data, the highest non-toxic concentrations of each sample were used in the following wound healing assay.

\subsection{Wound Healing Properties of S. macrophylla Seeds}

Following the cytotoxicity assessment, the wound healing properties of S. macrophylla were explored. Briefly, the assay was conducted by creating a scratch wound on $\mathrm{HaCaT}$ cells using a pipette tip and then treating the cells with the highest non-toxic concentration of each sample for $24 \mathrm{~h}$. The cells were also starved during the treatment period, except for the positive control, where $20 \%$ FBS was added to the media to induce cell growth 
and migration. Images of the wound were taken at time 0 and after $24 \mathrm{~h}$, and the area of closure was calculated using ImageJ. As depicted in Figure 2, all the samples were able to induce significant wound closure in HaCaT cells. SMCE at a concentration of $6.25 \mu \mathrm{g} / \mathrm{mL}$ displayed $54.10 \pm 2.59 \%$ wound area closure, while $100 \mu \mathrm{g} / \mathrm{mL}$ SMHF was able to induce $59.45 \pm 5.72 \%$ area closed. Meanwhile, $12.5 \mu \mathrm{g} / \mathrm{mL}$ SMEAF was able to close the wound by $41.48 \pm 3.91 \%$, and finally, $50 \mu \mathrm{g} / \mathrm{mL}$ SMWF displayed a $74.68 \pm 5.16 \%$ wound area closure. Representative images of wound closure by each sample and control can also be seen in Figure 3, supporting that S. macrophylla seed extract does possess wound healing properties.

(A)

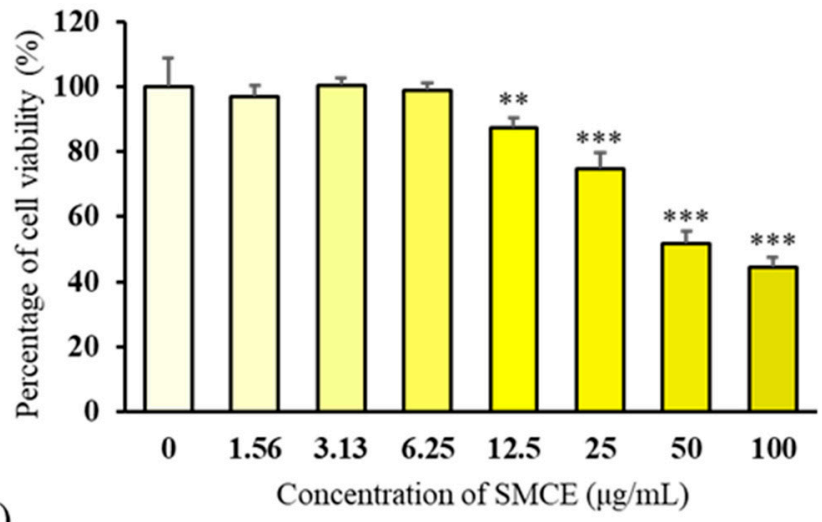

(C)

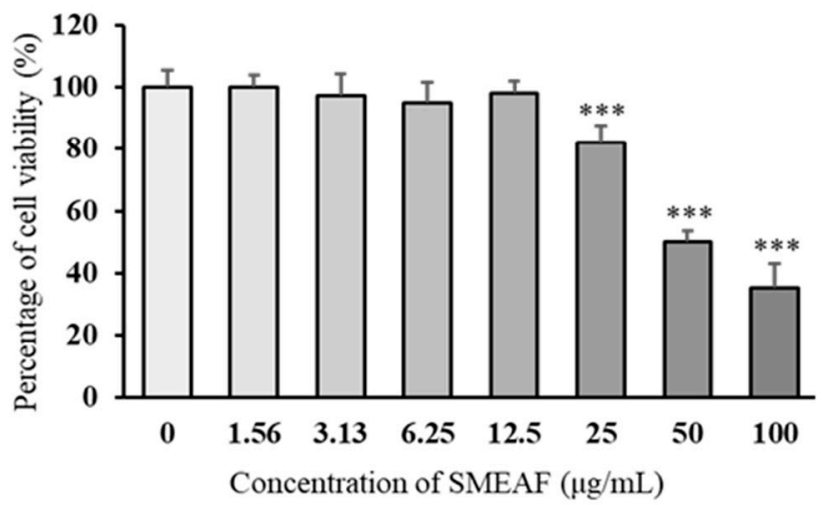

(B)

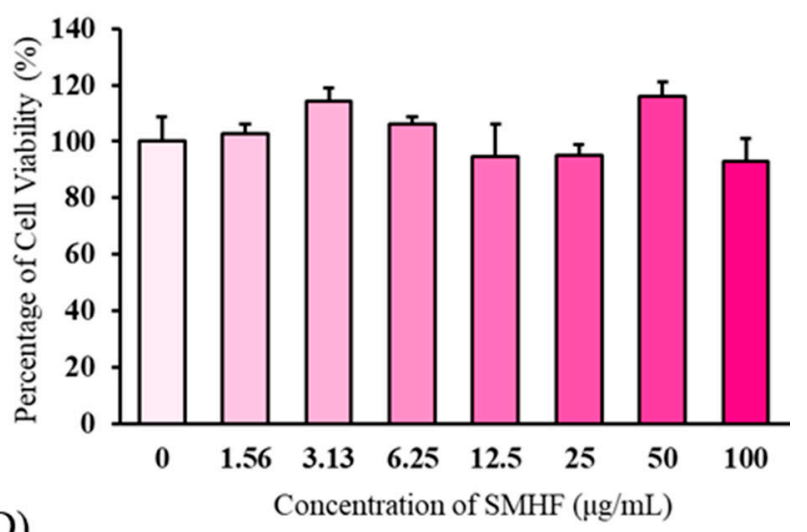

(D)

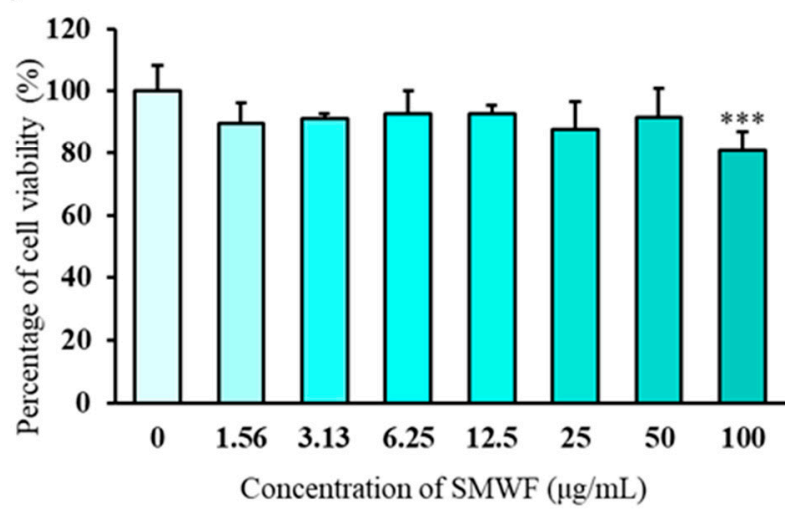

Figure 1. The cytotoxicity of each extract and its fractions on HaCaT cells after $24 \mathrm{~h}$ of treatment. The cells were seeded at a density of $1 \times 10^{5}$ cells $/ \mathrm{mL}$ and they were treated with varying concentrations $(0-100 \mu \mathrm{g} / \mathrm{mL})$ of (A) SMCE, (B) SMHF, (C) SMEAF, and (D) SMWF. The percentage of cell viability was measured using the MTT assay. $n>3$; ** $p \leq 0.01$; *** $p \leq 0.001$. Data were expressed as mean $\pm \mathrm{SD}$.

\subsection{Analysis of Antioxidant Properties of S. macrophylla Seed Extract}

Other than analyzing the wound healing properties of $S$. macrophylla extract and its fractions, its antioxidant properties were studied as well using antioxidant assays, such as iron chelating, DPPH radical scavenging, and ABTS radical scavenging (Table 1 summarizes the results). Gallic acid or EDTA were used as positive controls. Based on the data obtained, only SMWF demonstrated significant DPPH radical scavenging activity $(6.332 \pm 0.80 \%$ at $2000 \mu \mathrm{g} / \mathrm{mL}$ ), suggesting that it has the ability to donate hydrogen. Similarly, the ABTS assay also illustrated the antioxidant potential of SMWF; it significantly increased, in a dose-dependent manner, from $12.796 \pm 2.01$ to $29.946 \pm 0.47 \%$. The other fractions did not display any significant DPPH or ABTS radical scavenging activity. Finally, when the fractions were tested for iron chelating properties, both SMWF and SMHF displayed significant iron chelating activity. SMWF showed dose-dependent increase in iron chelating activity from $8.014 \pm 2.51$ to $23.523 \pm 1.94 \%$. As for SMHF, $2 \mathrm{mg} / \mathrm{mL}$ displayed significant 
$14.073 \pm 0.18 \%$ iron chelating activity as compared with the control. This suggests that both fractions contained antioxidant compounds that could chelate prooxidant iron ions.

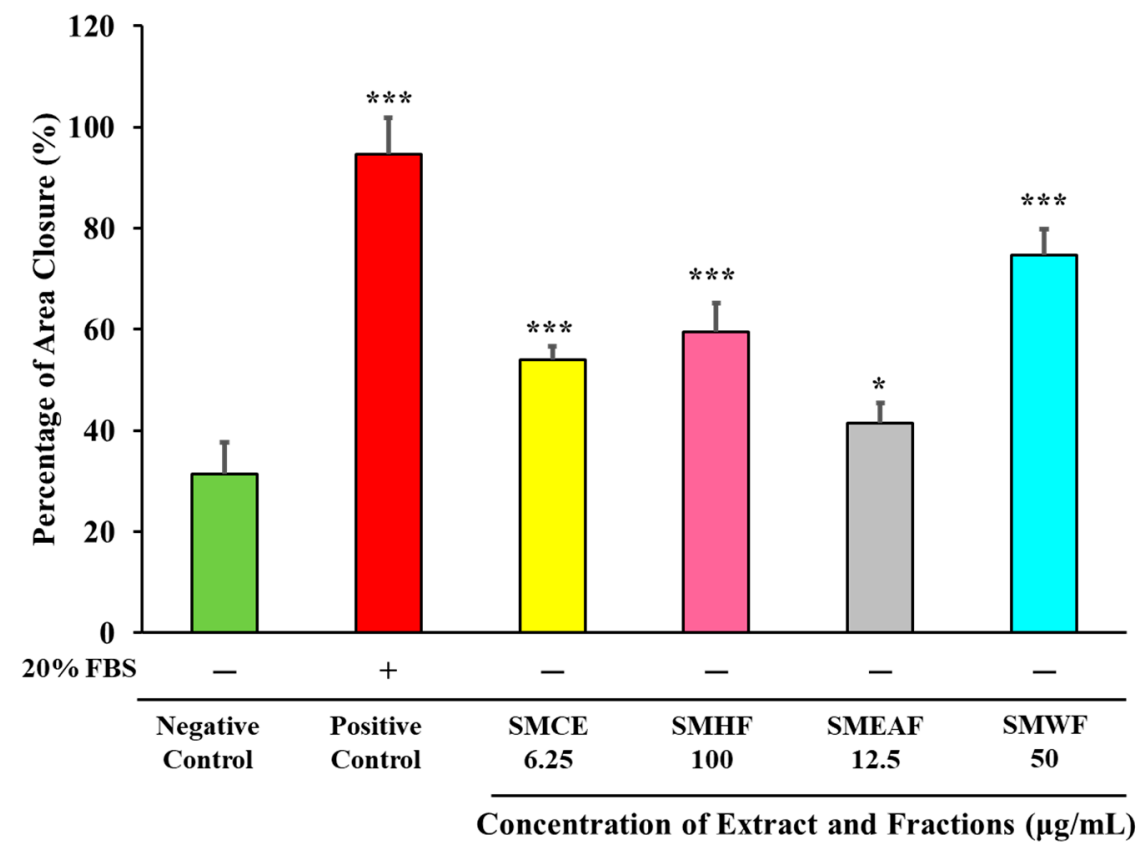

Figure 2. Wound healing properties of S. macrophylla seed on HaCaT cells determined via the scratch wound assay. After scratching, the cells, except the positive control, were starved and treated with the highest non-cytotoxic concentration of each sample (SMCE: $6.25 \mu \mathrm{g} / \mathrm{mL}$, SMHF: $100 \mu \mathrm{g} / \mathrm{mL}$, SMEAF: $12.5 \mu \mathrm{g} / \mathrm{mL}$ and SMWF: $50 \mu \mathrm{g} / \mathrm{mL}$ ) for $24 \mathrm{~h}$. The positive control was treated with $20 \% \mathrm{FBS}$, while the negative control was not treated with any sample or FBS. The significance of the wound area closed for each sample and positive control was compared against the negative control. $n>3$; ${ }^{*} p \leq 0.05 ;{ }^{* *} p \leq 0.001$. Data were expressed as mean $\pm \mathrm{SD}$.

Phenolic compounds are bioactive compounds, which contain an aromatic ring that has either one or more than one hydroxyl group attached to it [31]. It can also be easily found in higher plants and is known to possess antioxidant properties [32]. As SMWF had displayed antioxidant properties, the total phenolic content in the fraction was measured, and a correlation between the antioxidant potential and the total phenolic content was calculated using Pearson's correlation coefficient. As can be seen in Table 2, there was a strong correlation between SMWF's total phenolic content and the DPPH radical scavenging activity, ABTS radical scavenging activity, and the iron chelating activity of SMWF. This suggests that the antioxidant properties of SMWF could largely be attributed to the phenolic compounds present in the fraction. However, confirmation on the presence of these phenolic compounds in SMWF would require further purification, isolation and identification studies such as nuclear magnetic resonance (NMR) and x-ray crystallography analysis.

\subsection{Potential Photoprotective Properties of S. macrophylla Extract and Its Fractions}

In the development of broad-spectrum UV protection products, one of the criteria, according to U.S. Food and Drug Administration (FDA) and International Organization for Standardization (ISO), is to measure the critical wavelength $\left(\lambda_{c}\right)$ of the product to determine if it is able to absorb within the range of both UVA and UVB. According to the data that we obtained (Figure 4), SMWF had the broadest coverage of UVA and UVB with a $\lambda_{c}$ of $362.4 \mathrm{~nm}$. The second highest coverage was SMCE at $347.6 \mathrm{~nm}$, followed by SMHF at $345 \mathrm{~nm}$, and finally SMEAF at $341.6 \mathrm{~nm}$. Although neither sample reached the critical wavelength of $\geq 370 \mathrm{~nm}$ set by ISO and FDA, the samples SMCE, SMWF, and SMEAF showed high amplitude of absorbing UVB rays. Among all four samples, SMHF had the lowest amplitude although having a critical wavelength of $345 \mathrm{~nm}$. 


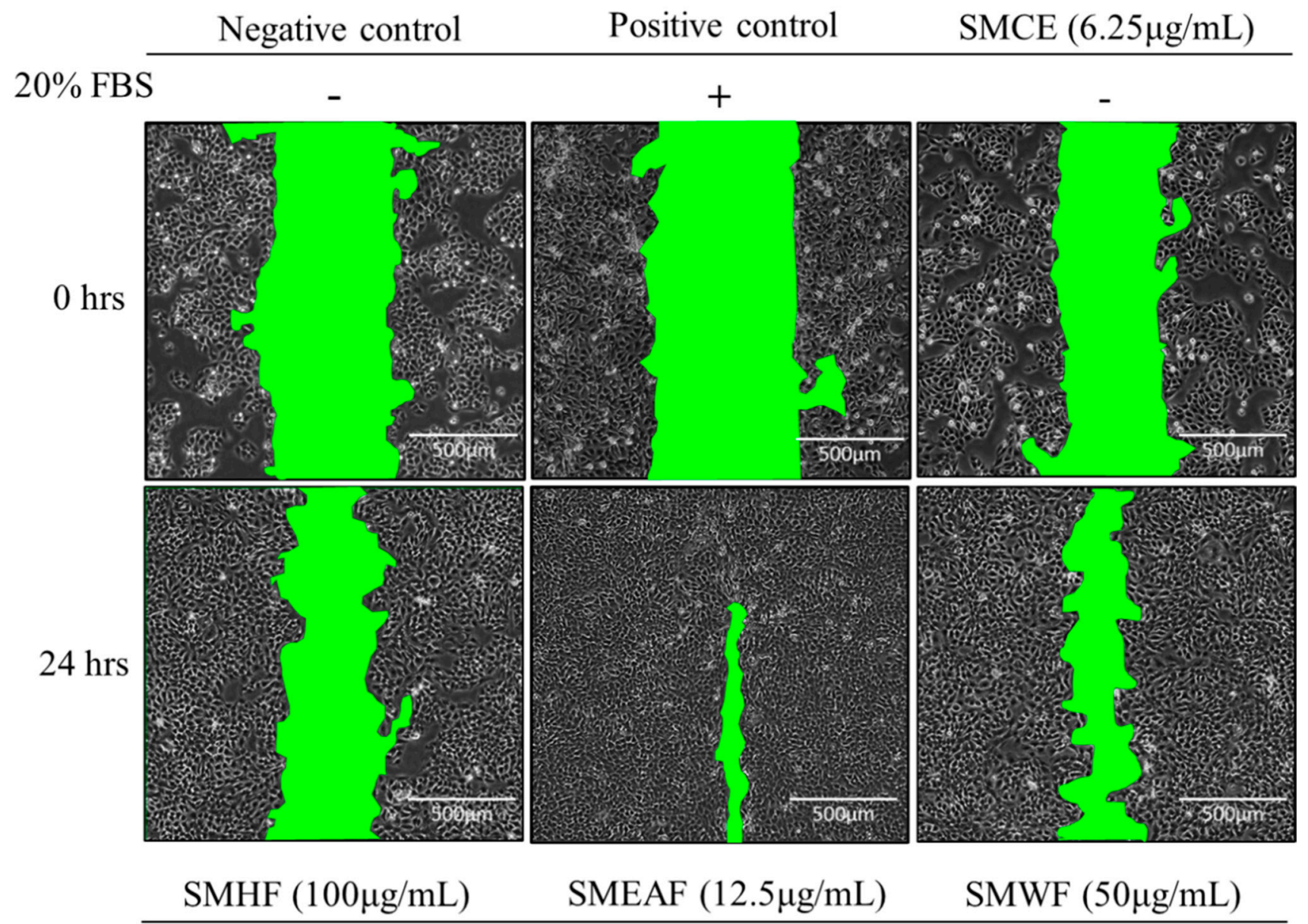

\section{$20 \%$ FBS}
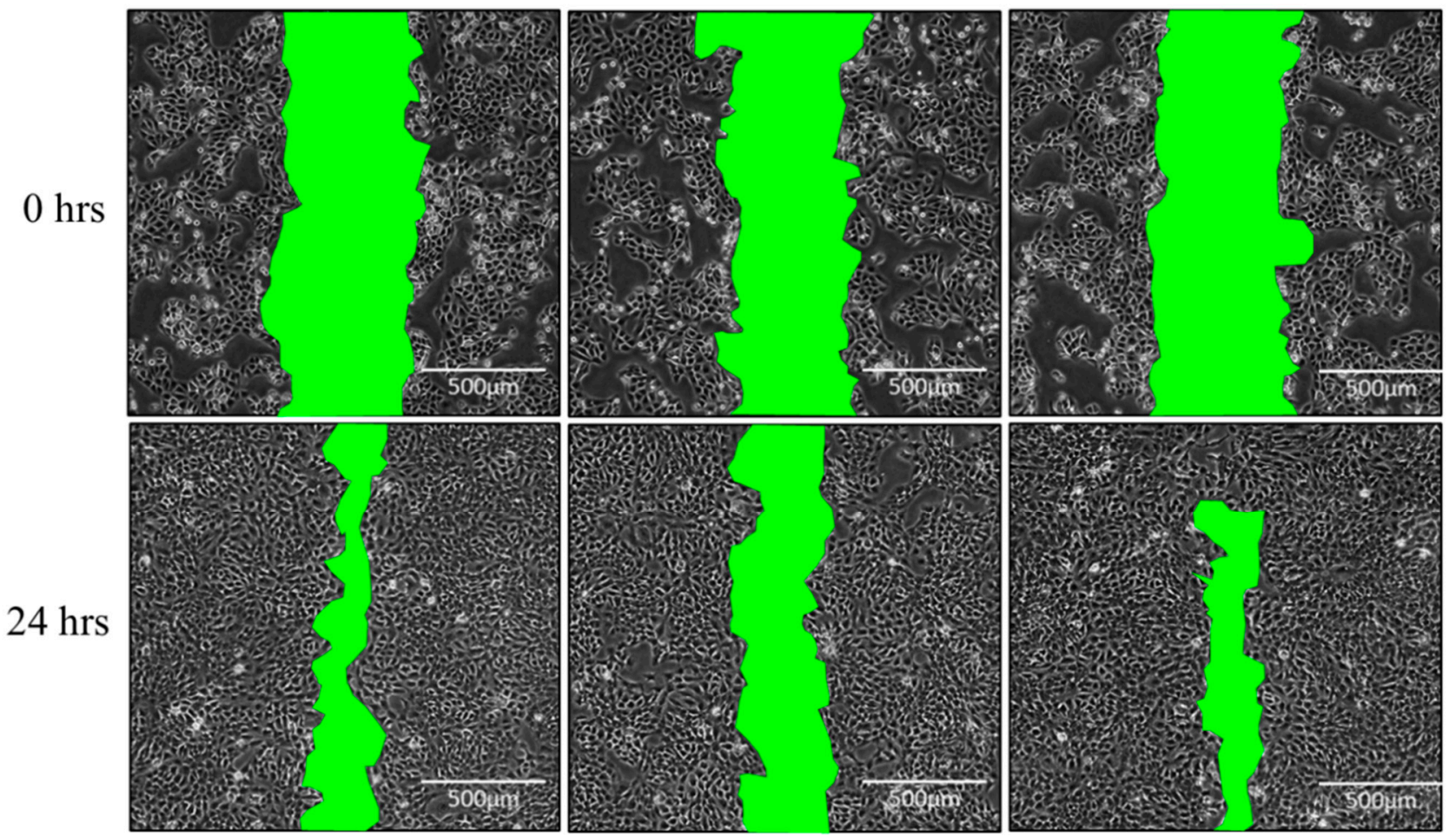

Figure 3. Images of wound area closed by SMCE, SMHF, SMEAF, and SMWF in the wound healing assay after $24 \mathrm{~h}$ of treatment. All cells, except the positive control, were not treated with $20 \%$ FBS. The green highlight depicted in this figure showcase the scratch wound areas created at $0 \mathrm{~h}$ and the wound closure seen at $24 \mathrm{~h}$. 
Table 1. Antioxidant potential of S. macrophylla extract and its fractions demonstrated in various antioxidant assays.

\begin{tabular}{|c|c|c|c|c|}
\hline Sample & $\begin{array}{c}\text { Concentration } \\
(\mu \mathrm{g} / \mathrm{mL})\end{array}$ & $\begin{array}{c}\text { DPPH Radical } \\
\text { Scavenging } \\
\text { Activity (\%) }\end{array}$ & $\begin{array}{l}\text { ABTS Radical } \\
\text { Scavenging } \\
\text { Activity (\%) }\end{array}$ & $\begin{array}{c}\text { Iron Chelating } \\
\text { Activity (\%) }\end{array}$ \\
\hline \multirow{5}{*}{ SMCE } & 125 & ND & $3.878 \pm 1.26$ & $1.738 \pm 0.55$ \\
\hline & 250 & ND & ND & ND \\
\hline & 500 & ND & ND & ND \\
\hline & 1000 & $3.581 \pm 3.45$ & ND & ND \\
\hline & 2000 & $4.523 \pm 1.64$ & ND & ND \\
\hline \multirow{5}{*}{ SMHF } & 125 & ND & ND & ND \\
\hline & 250 & ND & ND & ND \\
\hline & 500 & ND & $0.662 \pm 2.00$ & $3.830 \pm 0.27$ \\
\hline & 1000 & ND & $2.523 \pm 1.55$ & $4.638 \pm 1.56$ \\
\hline & 2000 & ND & $6.082 \pm 0.54$ & $14.073 \pm 0.18 *$ \\
\hline \multirow{5}{*}{ SMEAF } & 125 & ND & $3.130 \pm 1.14$ & $0.959 \pm 2.38$ \\
\hline & 250 & ND & ND & ND \\
\hline & 500 & ND & ND & ND \\
\hline & 1000 & ND & ND & ND \\
\hline & 2000 & $0.377 \pm 1.15$ & ND & ND \\
\hline \multirow{5}{*}{ SMWF } & 125 & ND & $12.796 \pm 2.01$ * & $8.014 \pm 2.51 *$ \\
\hline & 250 & ND & $14.252 \pm 3.37$ * & $10.366 \pm 0.38 *$ \\
\hline & 500 & $0.452 \pm 1.82$ & $18.297 \pm 3.01$ * & $12.01 \pm 1.95 *$ \\
\hline & 1000 & $2.978 \pm 0.90$ & $20.077 \pm 0.93 *$ & $15.531 \pm 2.19$ * \\
\hline & 2000 & $6.332 \pm 0.80 *$ & $29.946 \pm 0.47 *$ & $23.523 \pm 1.94$ * \\
\hline Gallic acid $^{1}$ & 10 & $42.158 \pm 2.03 *$ & $44.578 \pm 0.58 *$ & $\mathrm{~N} / \mathrm{A}$ \\
\hline EDTA $^{1}$ & 50 & $\mathrm{~N} / \mathrm{A}$ & $\mathrm{N} / \mathrm{A}$ & $24.821 \pm 1.14$ * \\
\hline
\end{tabular}

1 The positive control for the DPPH and ABTS assay was gallic acid, while EDTA was the positive control for the ferrous ion chelating assay. * Statistical significance was determined by comparing against the negative control group (blank), $p<0.05 ; \mathrm{ND}=$ not detected; $n \geq 3$.

Table 2. The Pearson's correlation coefficients between the antioxidant properties of SMWF and total phenolic content.

\begin{tabular}{cc}
\hline Antioxidant Activities & Total Phenolic Content \\
\hline DPPH radical scavenging activity & $r=0.935^{*}$ \\
ABTS radical scavenging activity & $r=0.903 *$ \\
Iron chelating activity & $r=0.915^{*}$ \\
\hline *Correlation is considered statistically significant at $p<0.05$.
\end{tabular}



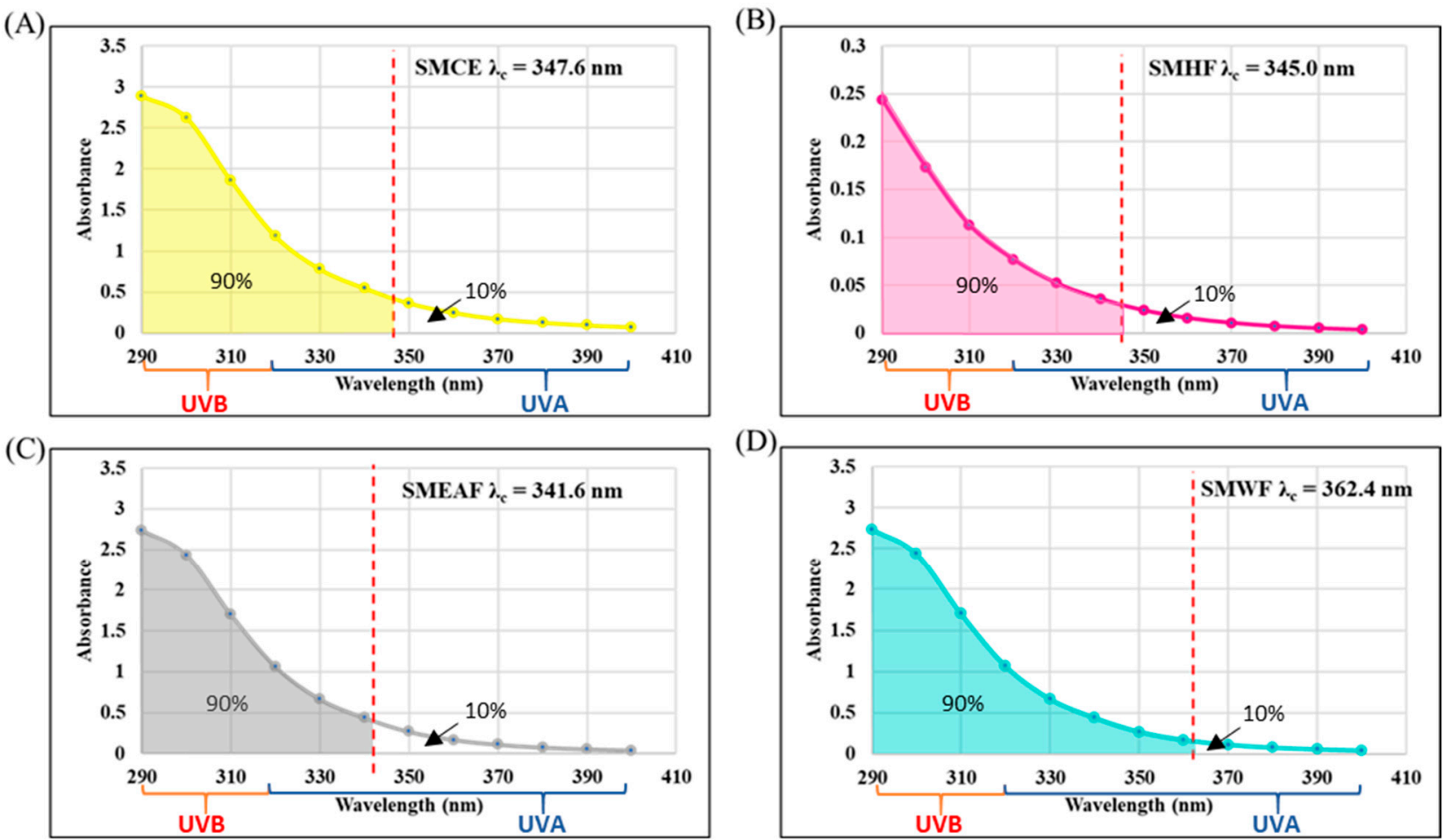

Figure 4. The absorbances and critical wavelengths of (A) SMCE (B) SMHF (C) SMEAF, and (D) SMWF within the range of 290-400 nm. The critical wavelength represents the point where the area under the curve reaches $90 \%$ for each sample. All samples were dissolved in 100\% DMSO to obtain a concentration of $40 \mathrm{mg} / \mathrm{mL}$ before the absorbance was measured. The absorbances obtained were normalized against the absorbance of DMSO.

\section{Discussion}

The natural course of a successful wound healing process can be segregated into four overlapping phases: (1) hemostasis, (2) inflammation, (3) proliferation, and (4) remodeling. When a wound is formed on the skin, vasoconstriction of blood vessels occurs to reduced blood loss. After 5-10 min, the blood vessels are dilated and increased in permeability for enabling inflammatory cells to migrate into the wound area. A blood clot is also formed to further reduce blood loss. Inflammation of the wound occurs to prevent infection and persists as long as needed to remove bacteria and debris from the wound. At the proliferation stage, complex processes of angiogenesis, collagen deposition, epithelialization, formation of granulation tissue, and wound retraction take place to repair the wound. Finally, at the remodeling stage, collagen III is replaced by collagen I and other proteins are deposited and organized in the wound to regain a structure similar to an unwounded tissue $[33,34]$.

Over the years, many natural products have been explored for potential wound healing properties and it has been found that natural products possessing antioxidant, antimicrobial, anti-inflammatory, and collagen-synthesis-increasing properties can speed up the process of wound healing [35-38]. In this study, the ability of the extract to induce cell proliferation and migration was determined via a scratch wound assay. In this experiment, $\mathrm{HaCaT}$, an immortalized human keratinocyte cell line, is utilized to emulate the epidermis of the skin. The cells that were seeded and, after $24 \mathrm{~h}$, scratched with a $0.5-10 \mu \mathrm{L}$ pipette tip to create a scratch wound. The cells were then treated with the highest non-toxic concentration of SMCE, SMHF, SMEAF, and SMWF. The area of wound closure was monitored and measured after $24 \mathrm{~h}$. As can be seen in both Figures 2 and 3, all samples were able to significantly reduce the wound area after $24 \mathrm{~h}$ as compared with the negative control, suggesting that $S$. macrophylla seed extract has bioactive compounds that can induce keratinocyte cell proliferation and migration. This claim is also supported by the study by Nilugal et al. [39], where wounded rats treated with S. macrophylla ethanolic seed extract displayed accelerated wound healing and repair compared with those that 
were not treated. However, our study showed the potential not only within the ethanolic extract alone but also upon its fractionation, which further enhanced the wound healing capabilities of $S$. macrophylla as compared with the crude extract. This ability was especially prominent in SMHF and SMWF as wounds with those fractions were almost closed after $24 \mathrm{~h}$. This demonstrated that most of the compounds responsible for the seed's wound healing capabilities were in these two fractions. It is also interesting that the highest rate of healing observed for SMWF could be potentially due to the antioxidant properties of this fraction. Antioxidants are important in the process of wound healing as they can suppress inflammation by inhibiting the excessive formation of ROS and aid the transition of the wound towards the proliferative phase [40]. This was clear when wounded diabetic rats, in a study by Musalmah et al. [41], experienced accelerated wound closure and increased antioxidant enzyme levels when treated with vitamin E, a well-known antioxidant. Thus, antioxidants can be considered as "accelerators" or "enhancers" in the repair process of chronic wounds. Previously, several phytocompounds extracted from the seed of $S$. macrophylla were found to have antioxidant properties, namely, swietenolide, 3,6-O,O-diacetlyswietenolide, swietenine, 2-hydroxyswietenine, and swietemahonin G, swietenolide having the strongest antioxidant effect in comparison with the rest [42]. In addition, swietenine was recently reported also in another study to boost the total antioxidant capacity in the serum of diabetic rats [43]. As these compounds were found in the seed of $S$. macrophylla, it could be possible that these antioxidant compounds might be involved in the accelerated wound healing. However, confirmation of these compounds and the mechanism behind the wound healing properties of $S$. macrophylla fractions would require further analysis.

On another note, one of the key extrinsic factors that lead to skin aging is photodamage by the sun. Constant exposure to ultraviolet rays, such as UVA and UVB, not only causes simple sunburn or skin erythema but also induces pigment abnormalities, keratinocyte hyperplasia, photoaging, and even skin cancer $[44,45]$. Although UVA has the longest wavelength (320-400 nm) and is able to penetrate to the dermis layer, it is not as detrimental as UVB. UVB (290-320 nm), although being able to penetrate only the epidermis layer, was found to be able to cause direct damage to the skin cells by forming pyrimidinepyrimidone (6-4) photoproduct and cyclobutene pyrimidine dimers (CPD) in DNA [46]. Besides that, the exposure of both UVB and UVA increases the production of reactive oxygen species (ROS) and reactive nitrogen species (RNS) in the skin. [47-49]. This quickly leads to increased oxidative and nitrosative stress in the skin, which brings about a cascade of events, such skin inflammation, collagen degradation, increased melanin production, and cell death [50-54].

Therefore, a way to attenuate photoaging is by applying sunscreen. There are two types of sunscreens that are available on the market: physical and chemical sunscreen. The main attributes of a physical sunscreen are to reflect, scatter, and physically block UV rays, while a chemical sunscreen absorbs the UV rays and dissipates the energy through photophysical and/or photochemical pathways that do not form ROS or damage reactive intermediates $[55,56]$. Following the FDA and ISO guidelines, the strength of a chemical sunscreen can be determined through its ability to absorb UV wavelengths ranging from 290 to $400 \mathrm{~nm}$. Broad-spectrum sunscreen must also have a critical wavelength equaling to or more than $370 \mathrm{~nm}$. This is to indicate that the product is capable of absorbing between 290-370 mm, which is most of the UVB range [57-59].

In this study, to measure the critical wavelength, the absorbance of samples was measured in a UV transmittable 96-well plate using a UV/Vis spectrophotometer. The absorbance was measured from 290 to $400 \mathrm{~nm}$ (in accordance with the wavelengths of both UVA and UVB). The critical wavelength of each sample was then analyzed using the formula designed by Diffey [30] and the MATLAB software. This analysis was in accordance with the method that we had previously developed, in which photoprotective compounds, such as pinocembrin and caffeic acid, were discovered to have a critical wavelength of $364.8 \mathrm{~nm}$ and $378.2 \mathrm{~nm}$, respectively. The data obtained were then in turn 
compared with existing literature, which further confirmed the accuracy of the test [29]. There are several advantages in conducting this form of analysis: (1) it measures not only the amplitude but also the width of the product's absorption spectrum, (2) the measurement is not affected by the application thickness of the product, and (3) it can account for both UVA and UVB as a single entity in a continuous electromagnetic spectrum [60]. Finally, in vitro methods of measurement are recommended by the FDA as they have reduced dangers, cost, and time consumption relative to human clinical testing [59].

After analyzing the critical wavelength of all samples, we found that SMWF, with a critical wavelength of $362.4 \mathrm{~nm}$, had the broadest absorption range of UVA and UVB. This is followed by SMCE, SMHF, and finally SMEAF with 347.6, 345.0, and $341.6 \mathrm{~nm}$ respectively. SMCE, SMEAF, and SMWF also displayed high amplitude of absorption within the UVB range in comparison with SMHF. Previously, there had been suggestions that the extract of $S$. macrophylla seeds had photoprotective properties. This can be seen in the research by Mahendra et al. [61], where the seed extract displayed the ability to attenuate the damaging effect of UVB on human skin at a molecular level. Hence, although not reaching the critical value of $370 \mathrm{~nm}$, photoprotective bioactive compounds might be present within the S. macrophylla seed extract and its fractions. Thus, this warrants further fractionation, purification, and investigation of the bioactive principles of $S$. macrophylla.

\section{Conclusions}

In summary, we have shown that S. macrophylla extract and its fractions have wound healing properties on HaCaT cells, with SMHF and SMWF being some of the most effective ones among the fractions. Subsequently, it had been suggested that the increased wound healing capacity of SMWF could also be due to the presence of antioxidants in the fraction itself, which can aid in suppressing the inflammatory pathway. Despite that, the mechanism and compounds responsible for the wound healing ability of S. macrophylla had yet to be elucidated and this warrants further studies. Aside from that, all samples were able to absorb within the UVB range and some wavelengths in the UVA range, which suggests that there may be potential photoprotective bioactive compounds within the S. macrophylla extract and its fractions. Therefore, for future studies, further separation, isolation, and identification of these bioactive compounds responsible for these properties are recommended. After the identification and enhancement of its properties, there is a potential that the bioactive compound found could be used as an active therapeutic ingredient in future cosmeceutical products.

Author Contributions: Conceptualization, B.H.G. and C.K.M. (Camille Keisha Mahendra); Methodology, C.K.M. (Camille Keisha Mahendra) and L.T.H.T.; Formal Analysis, C.K.M. (Camille Keisha Mahendra), L.T.H.T. and C.K.M.; Investigation, C.K.M.; Writing-Original Draft Preparation, C.K.M. (Cayvern Kishen Mahendra); Writing—Review \& Editing, H.-L.S., P.P., T.T.H., L.-H.C., W.H.Y., S.Y.T., L.C.M. and B.H.G.; Supervision, B.H.G.; Project Administration, B.H.G. and C.K.M. (Camille Keisha Mahendra); Funding Acquisition, P.P., T.T.H., L.-H.C., W.H.Y., L.C.M., S.Y.T., Y.-Y.Y. and B.H.G. All authors have read and agreed to the published version of the manuscript.

Funding: This work was financially supported by Taylor's University Emerging Grant (TRGS/ERFS/ 2/2018/SBS/016), External Industry Grants from Biotek Abadi Sdn Bhd (vote no. GBA-81811A), Monash Global Asia in the 21st Century (GA21) research grant (GA-HW-19-L01 \& GA-HW-19-S02) and Fundamental Research Grant Scheme (FRGS/1/2019/WAB09/MUSM/02/1 and FRGS/1/2019/ SKK08/TAYLOR/02/2).

Institutional Review Board Statement: Not applicable.

Informed Consent Statement: Not applicable.

Data Availability Statement: The data used to support the findings of this study are available from the corresponding author upon request. 
Conflicts of Interest: The authors declare that no conflict of interest exists. The funders had no role in the design of the study; in the collection, analyses, or interpretation of data; in the writing of the manuscript, or in the decision to publish the results.

\section{References}

1. Vecino, X.; Cruz, J.M.; Moldes, A.B.; Rodrigues, L.R. Biosurfactants in cosmetic formulations: Trends and challenges. Crit. Rev. Biotechnol. 2017, 37, 911-923. [CrossRef]

2. Amberg, N.; Fogarassy, C. Green consumer behavior in the cosmetics market. Resources 2019, 8, 137. [CrossRef]

3. Ho, H.-C.; Chiu, C.L.; Mansumitrchai, S.; Quarles, B.J. Hedonic and utilitarian value as a mediator of men's intention to purchase cosmetics. J. Glob. Fash. Mark. 2020, 11, 71-89. [CrossRef]

4. Scharffetter-Kochanek, K.; Brenneisen, P.; Wenk, J.; Herrmann, G.; Ma, W.; Kuhr, L.; Meewes, C.; Wlaschek, M. Photoaging of the skin from phenotype to mechanisms. Exp. Gerontol. 2000, 35, 307-316. [CrossRef]

5. Draelos, Z.D. The latest cosmeceutical approaches for anti-aging. J. Cosmet. Dermatol. 2007, 6, 2-6. [CrossRef]

6. Guinot, C.; Malvy, D.J.M.; Ambroisine, L.; Latreille, J.; Mauger, E.; Tenenhaus, M.; Morizot, F.; Lopez, S.; Le Fur, I.; Tschachler, E. Relative contribution of intrinsic vs extrinsic factors to skin aging as determined by a validated skin age score. Arch. Dermatol. 2002, 138, 1454-1460. [CrossRef]

7. Papakonstantinou, E.; Roth, M.; Karakiulakis, G. Hyaluronic acid: A key molecule in skin aging. Derm. Endocrinol. 2012, 4, 253-258. [CrossRef] [PubMed]

8. Martin, K.I.; Glaser, D.A. Cosmeceuticals: The new medicine of beauty. MO Med. 2011, 108, 60-63. [PubMed]

9. Smirnova, M.H. A will to youth: The woman's anti-aging elixir. Soc. Sci. Med. 2012, 75, 1236-1243. [CrossRef] [PubMed]

10. Ghazali, E.; Soon, P.C.; Mutum, D.S.; Nguyen, B. Health and cosmetics: Investigating consumers' values for buying organic personal care products. J. Retial. Consum. Serv. 2017, 39, 154-163. [CrossRef]

11. Dorni, A.I.C.; Augustine, A.; Sreeraj, G.; Varma, K.; Anjana, S.N. Novel cosmeceuticals from plants-An industry guided review. J. Appl. Res. Med. Aromat. Plants 2017, 7, 1-26. [CrossRef]

12. Gangemi, E.N.; Gregori, D.; Berchialla, P.; Zingarelli, E.; Cairo, M.; Bollero, D.; Ganem, J.; Capocelli, R.; Cuccuru, F.; Cassano, P.; et al. Epidemiology and risk factors for pathologic scarring after burn wounds. Arch. Facial Plast. Surg. 2008, 10, 93-102. [CrossRef]

13. Rivera, A.E. Acne scarring: A review and current treatment modalities. J. Am. Acad. Dermatol. 2008, 59, 659-676. [CrossRef]

14. Yu, P.-X.; Diao, W.-Q.; Qi, Z.-L.; Cai, J.-L. Effect of dermabrasion and ReCell ${ }^{\circledR}$ on large superficial facial scars caused by burn, trauma and acnes. Chin. Med. Sci. J. 2016, 31, 173-179. [CrossRef]

15. Garg, V.K.; Sinha, S.; Sarkar, R. Glycolic acid peels versus salicylic-mandelic acid peels in active acne vulgaris and post-acne scarring and hyperpigmentation: A comparative study. Dermatol. Surg. 2009, 35, 59-65. [CrossRef] [PubMed]

16. Wang, L.-Z.; Ding, J.-P.; Yang, M.-Y.; Chen, D.-W.; Chen, B. Treatment of facial post-burn hyperpigmentation using micro-plasma radiofrequency technology. Lasers Med. Sci. 2015, 30, 241-245. [CrossRef] [PubMed]

17. Akita, S.; Akino, K.; Imaizumi, T.; Hirano, A. Basic fibroblast growth factor accelerates and improves second-degree burn wound healing. Wound Repair Regen. 2008, 16, 635-641. [CrossRef] [PubMed]

18. Wu, S.F.; Lin, C.K.; Chuang, Y.S.; Chang, F.R.; Tseng, C.K.; Wu, Y.C.; Lee, J.C. Anti-hepatitis C virus activity of 3-hydroxy caruilignan C from Swietenia macrophylla stems. J. Viral Hepat. 2012, 19, 364-370. [CrossRef]

19. Cheng, Y.-B.; Chien, Y.-T.; Lee, J.-C.; Tseng, C.-K.; Wang, H.-C.; Lo, I.-W.; Wu, Y.-H.; Wang, S.-Y.; Wu, Y.-C.; Chang, F.-R. Limonoids from the seeds of Swietenia macrophylla with inhibitory activity against dengue virus 2. J. Nat. Prod. 2014, 77, 2367-2374. [CrossRef]

20. Goh, B.H.; Abdul Kadir, H. In vitro cytotoxic potential of Swietenia macrophylla King seeds against human carcinoma cell lines. J. Med. Plant Res. 2011, 5, 1395-1404. [CrossRef]

21. Low, D.Y.S.; Mahendra, C.K.; Supramaniam, J.; Tan, L.T.H.; Lee, L.H.; Manickam, S.; Goh, B.H.; Tan, K.W.; Tang, S.Y. Ultrasoundenhanced biosynthesis of uniform $\mathrm{ZnO}$ nanorice using Swietenia macrophylla seed extract and its in vitro anticancer activity. Nanotechnol. Rev. 2021, 10, 572-585. [CrossRef]

22. Sayyad, M.; Tiang, N.; Kumari, Y.; Goh, B.H.; Jaiswal, Y.; Rosli, R.; Williams, L.; Shaikh, M.F. Acute toxicity profiling of the ethyl acetate fraction of Swietenia macrophylla seeds and in-vitro neuroprotection studies. Saudi Pharm. J. 2017, 25, 196-205. [CrossRef] [PubMed]

23. Hashim, A.; Yam, M.F.; Hor, S.Y.; Lim, C.P.; Asmawi, M.Z.; Sadikun, A. Anti-hyperglycaemic activity of Swietenia macrophylla King (Meliaceae) seed extracts in normoglycaemic rats undergoing glucose tolerance tests. Chin. Med. 2013, 8, 11. [CrossRef]

24. Goh, B.H.; Chan, C.K.; Kamarudin, M.N.A.; Abdul Kadir, H. Swietenia macrophylla King induces mitochondrial-mediated apoptosis through p53 upregulation in HCT116 colorectal carcinoma cells. J. Ethnopharmacol. 2014, 153, 375-385. [CrossRef]

25. Tan, L.T.-H.; Chan, K.-G.; Khan, T.M.; Bukhari, S.I.; Saokaew, S.; Duangjai, A.; Pusparajah, P.; Lee, L.-H.; Goh, B.-H. Streptomyces sp. MUM212 as a Source of Antioxidants with Radical Scavenging and Metal Chelating Properties. Front. Pharmacol. 2017,8 , 276. [CrossRef] [PubMed]

26. Lee, C.; Park, G.H.; Ahn, E.M.; Park, C.-I.; Jang, J.-H. Sargassum fulvellum protects HaCaT cells and BALB/c mice from UVB-induced proinflammatory responses. Evid. Based Complementary Altern. Med. 2013, 2013, 747846. [CrossRef] [PubMed] 
27. Ser, H.-L.; Zainal, N.; Palanisamy, U.D.; Goh, B.-H.; Yin, W.-F.; Chan, K.-G.; Lee, L.-H. Streptomyces gilvigriseus sp. nov., a novel actinobacterium isolated from mangrove forest soil. Antonie van Leeuwenhoek 2015, 107, 1369-1378. [CrossRef]

28. Adjimani, J.P.; Asare, P. Antioxidant and free radical scavenging activity of iron chelators. Toxicol. Rep. 2015, 2, 721-728. [CrossRef]

29. Mahendra, C.K.; Mahendra, C.K.; Pusparajah, P.; Htar, T.-T.; Lay-Hong, C.; Duangjai, A.; Khan, T.M.; Yoon Yen, Y.; Kumari, Y.; Bey Hing, G. Simplified, cost effective, and accurate calculation of critical wavelength via the MATLAB software. Prog. Drug Discov. Biomed. Sci. 2021, 4, 1-16. [CrossRef]

30. Diffey, B.L. A method for broad spectrum classification of sunscreens. Int. J. Cosmet. Sci. 1994, 16, 47-52. [CrossRef]

31. Vermerris, W.; Nicholson, R. Families of phenolic compounds and means of classification. In Phenolic Compound Biochemistry; Springer: Dordrecht, The Netherlands, 2006; pp. 1-34.

32. Haminiuk, C.W.I.; Plata-Oviedo, M.S.V.; de Mattos, G.; Carpes, S.T.; Branco, I.G. Extraction and quantification of phenolic acids and flavonols from Eugenia pyriformis using different solvents. J. Food Sci. Technol. 2014, 51, 2862-2866. [CrossRef]

33. Singh, S.; Young, A.; McNaught, C.-E. The physiology of wound healing. Surgery 2017, 35, 473-477. [CrossRef]

34. Landén, N.X.; Li, D.; Ståhle, M. Transition from inflammation to proliferation: A critical step during wound healing. Cellular Mol. Life Sci. 2016, 73, 3861-3885. [CrossRef] [PubMed]

35. Shetty, S.; Udupa, S.; Udupa, L. Evaluation of antioxidant and wound healing effects of alcoholic and aqueous extract of Ocimum sanctum Linn in rats. Evid. Based Complementary Altern. Med. 2008, 5, 95-101. [CrossRef]

36. Dai, X.; Liu, J.; Zheng, H.; Wichmann, J.; Hopfner, U.; Sudhop, S.; Prein, C.; Shen, Y.; Machens, H.-G.; Schilling, A.F. Nanoformulated curcumin accelerates acute wound healing through Dkk-1-mediated fibroblast mobilization and MCP-1-mediated anti-inflammation. NPG Asia Mater. 2017, 9, e368. [CrossRef]

37. Panchatcharam, M.; Miriyala, S.; Gayathri, V.S.; Suguna, L. Curcumin improves wound healing by modulating collagen and decreasing reactive oxygen species. Mol. Cell Biochem. 2006, 290, 87-96. [CrossRef]

38. Reddy, B.S.; Reddy, R.K.K.; Naidu, V.G.M.; Madhusudhana, K.; Agwane, S.B.; Ramakrishna, S.; Diwan, P.V. Evaluation of antimicrobial, antioxidant and wound-healing potentials of Holoptelea integrifolia. J. Ethnopharmacol. 2008, 115, $249-256$. [CrossRef]

39. Nilugal, K.C.; Fattepur, S.; Asmani, M.F.; Abdullah, I.; Vijendren, S.; Ugandar, R.E. Evaluation of wound healing acitivity of Swietenia macrophylla (Meliaceae) seed extract in albino rats. J. Pharm. Tech. Res. 2017, 7, 113-124.

40. Xu, Z.; Han, S.; Gu, Z.; Wu, J. Advances and impact of antioxidant hydrogel in chronic wound healing. Adv. Healthc. Mater. 2020, 9, 1901502. [CrossRef] [PubMed]

41. Musalmah, M.; Fairuz, A.H.; Gapor, M.T.; Wan Ngah, W.Z. Effect of vitamin E on plasma malondialdehyde, antioxidant enzyme levels and the rates of wound closures during wound healing in normal and diabetic rats. Asia Pac. J. Clin. Nutr. 2002, 11, S448-S451. [CrossRef] [PubMed]

42. Fowles, R.G.; Mootoo, B.S.; Ramsewak, R.S.; Reynolds, W.F.; Nair, M.G. Limonoids from Meliaceae with lipid peroxidation inhibitory activity. Nat. Prod. Commun. 2011, 6, 785-787. [CrossRef] [PubMed]

43. Shiming, Z.; Mak, K.-K.; Balijepalli, M.K.; Chakravarthi, S.; Pichika, M.R. Swietenine potentiates the antihyperglycemic and antioxidant activity of Metformin in Streptozotocin induced diabetic rats. Biomed. Pharmacother. 2021, 139, 111576. [CrossRef] [PubMed]

44. Kielbassa, C.; Roza, L.; Epe, B. Wavelength dependence of oxidative DNA damage induced by UV and visible light. Carcinogenesis 1997, 18, 811-816. [CrossRef] [PubMed]

45. Salucci, S.; Burattini, S.; Buontempo, F.; Martelli, A.M.; Falcieri, E.; Battistelli, M. Protective effect of different antioxidant agents in UVB-irradiated keratinocytes. Eur. J. Histochem. 2017, 61, 2784. [CrossRef] [PubMed]

46. You, Y.-H.; Lee, D.-H.; Yoon, J.-H.; Nkajima, S.; Yasui, A.; Pfeifer, G.P. Cyclobutane pyrimidine dimers are responsible for the vast majority of mutations induced by UVB irradiation in mammalian cells. J. Biol. Chem. 2001, 276, 44688-44694. [CrossRef] [PubMed]

47. Kovacs, D.; Raffa, S.; Flori, E.; Aspite, N.; Briganti, S.; Cardinali, G.; Torrisi, M.R.; Picardo, M. Keratinocyte growth factor down-regulates intracellular ROS production induced by UVB. J. Dermatol. Sci. 2009, 54, 106-113. [CrossRef]

48. Hseu, Y.-C.; Chou, C.-W.; Senthil Kumar, K.J.; Fu, K.-T.; Wang, H.-M.; Hsu, L.-S.; Kuo, Y.-H.; Wu, C.-R.; Chen, S.-C.; Yang, H.-L. Ellagic acid protects human keratinocyte (HaCaT) cells against UVA-induced oxidative stress and apoptosis through the upregulation of the HO-1 and Nrf-2 antioxidant genes. Food Chem. Toxicol. 2012, 50, 1245-1255. [CrossRef]

49. Filip, G.A.; Postescu, I.D.; Bolfa, P.; Catoi, C.; Muresan, A.; Clichici, S. Inhibition of UVB-induced skin phototoxicity by a grape seed extract as modulator of nitrosative stress, ERK/NF-kB signaling pathway and apoptosis, in SKH-1 mice. Food Chem. Toxicol. 2013, 57, 296-306. [CrossRef]

50. Nylander, K.; Bourdon, J.-C.; Bray, S.E.; Gibbs, N.K.; Kay, R.; Hart, I.; Hall, P.A. Transcriptional activation of tyrosinase and TRP-1 by p53 links UV irradiation to the protective tanning response. J. Pathol. 2000, 190, 39-46. [CrossRef]

51. Imokawa, G. Recent advances in characterizing biological mechanisms underlying UV-induced wrinkles: A pivotal role of fibrobrast-derived elastase. Arch. Dermatol. Res. 2008, 300, 7-20. [CrossRef]

52. Bashir, M.M.; Sharma, M.R.; Werth, V.P. UVB and pro-inflammatory cytokines synergistically activate TNF- $\alpha$ production in keratinocytes through enhanced gene transcription. J. Investig. Dermatol. 2009, 129, 994-1001. [CrossRef]

53. Lee, C.-H.; Wu, S.-B.; Hong, C.-H.; Yu, H.-S.; Wei, Y.-H. Molecular mechanisms of UV-induced apoptosis and its effects on skin residential cells: The implication in uv-based phototherapy. Int. J. Mol. Sci. 2013, 14, 6414-6435. [CrossRef] 
54. Lai, X.; Wichers, H.J.; Soler-Lopez, M.; Dijkstra, B.W. Structure of human tyrosinase related protein 1 reveals a binuclear zinc active site important for melanogenesis. Angew. Chem. Int. Ed. Engl. 2017, 56, 9812-9815. [CrossRef]

55. Serpone, N.; Salinaro, A.; Emeline, A.V.; Horikoshi, S.; Hidaka, H.; Zhao, J. An in vitro systematic spectroscopic examination of the photostabilities of a random set of commercial sunscreen lotions and their chemical UVB/UVA active agents. Photochem. Photobiol. Sci. 2002, 1, 970-981. [CrossRef] [PubMed]

56. Djalil, A.D.; Ambarwati, T.; Genatrika, E. Characterization of sunscreen cream containing benzophenone-3, $3^{\prime}, 4,4^{\prime}$-tetracarboxylate dianhydride. IOP Conf. Ser. Mater. Sci. Eng. 2018, 434, 012090. [CrossRef]

57. ISO. ISO 24444:2010 Cosmetics-Sun Protection Test Methods-In Vivo Determination of the Sun Protection Factor (SPF). Available online: https://www.iso.org/obp/ui/\#iso:std:iso:24444:ed-1:v1:en (accessed on 10 August 2018).

58. FDA. Guidance for Industry Labelling and Effectiveness Testing: Sunscreen Drug Products for Over-the Counter Human UseSmall Entity Compliance Guide. Available online: https: / / www.fda.gov/drugs/guidancecomplianceregulatoryinformation/ guidances/ucm330694.htm (accessed on 10 August 2018).

59. Pelizzo, M.; Zattra, E.; Nicolosi, P.; Peserico, A.; Garoli, D.; Alaibac, M. In Vitro evaluation of sunscreens: An update for the clinicians. ISRN Dermatol. 2012, 2012, 352135. [CrossRef] [PubMed]

60. Diffey, B.L.; Tanner, P.R.; Matts, P.J.; Nash, J.F. In vitro assessment of the broad-spectrum ultraviolet protection of sunscreen products. J. Am. Acad. Dermatol. 2000, 43, 1024-1035. [CrossRef]

61. Mahendra, C.K.; Abidin, S.A.Z.; Htar, T.T.; Chuah, L.H.; Khan, S.U.; Ming, L.C.; Tang, S.Y.; Pusparajah, P.; Goh, B.H. Counteracting the ramifications of UVB irradiation and photoaging with Swietenia macrophylla King seed. Molecules 2021, 26, 2000. [CrossRef] [PubMed] 